\title{
The Influence of Ozone in Ventilation
}

\author{
Its Principal Function Seems to be that of a Deodorizer
}

\author{
By Leonard Hill, M.B., F,R.S., and Martin Flack, M.A., M.B., B.Ch.
}

THE good effects which result from efficient ventilation and open-air treatment are generally supposed to be due to the chemical purity of the air. They are due really to the movement, coolness, relative humidity of the air, and to the ceaseless variation of these qualities. The ventilating engineer has hitherto followed a great illusion in thinking that the main object to be attained is chemical purity of the air. The heating engineer has
sought after an equally great illusion in striving to give sought after an equally great illusion in striving to give
us a uniform summer temperature (Pembrey). The ventilating and heating engineers primarily should aim at giving us air which is cool, of proper relative humidity, and which moves so as to vary the cutaneous state of th body. Our comfort and discomfort in crowded rooms and shut-up places depend, not on the chemical purity of the air, but, to a minor degree, on the influence of the smell of the air on the olfactory sense, and, to a vast degree, on the influence of the temperature, relative degree, on the influence of the temperature, relative
humidity, and the variation of these qualities of the air, which act on the great field of cutaneous sensibility.

It is needless to point out that our sense of well-being depends to a very great degree on the comfortable condition of our skin, and yet the ventilating and heating engineers have paid little attention to this. While asserting that the chemical purity is of no account, we make
the proviso that the air is only altered by the presence the proviso that the air is only altered by the presence
of human beings, and is neither rendered poisonous by of human beings, and is neither rendered poisonous by
the escape of coal gas, or other noxious trade product nor deoxygenated by the oxidative processes of the soil, as it is in mines. We are speaking of the discomfort and ill-health caused by the deficient ventilation of, or bad methods of heating, dwelling-houses, schools, factories, theaters, chapels, etc.

The chemical purity of the air can be considered from three points of view, the concentration of $\mathrm{CO}_{2}$, the concentration of $\mathrm{O}_{2}$, the supposed presence of organic poison exhaled in the breath.

Owing to the fact that a percentage of $\mathrm{CO}_{2}$ is not legally permissible in factories which exceeds a very few parts per thousand, it is commonly supposed that any greater excess of $\mathrm{CO}_{2}$ acts as a poison.

The truth of the matter is quite otherwise; for, what ever the percentage of $\mathrm{CO}_{2}$ in the atmosphere may be, that in the pulmonary air is kept constant at about 5 per cent of an atmosphere by the action of the respiratory cent of an atmosphere by the action of the respiratory
center. It is the concentration of $\mathrm{CO}_{2}$ which rules the center. It is the concentration of $\mathrm{CO}_{2}$ which rules the
respiratory center, and to such purpose as to keep the concentration both in the lungs and in the blood uniformly about the same. This fact, which was first firmly established by Dr. John Haldane, is of fundamental importance.

It is impossible that any excess of $\mathrm{CO}_{2}$ should enter into our bodies when we breathe the air of the worstventilated room in which the percentage of $\mathrm{CO}_{2}$ assuredly ventilated room in which the percentage of $\mathrm{CO}_{2}$ assuredly
does not rise above 0.5 per cent, or at the outside 1 per does not rise above 0.5 per cent, or at the outside 1 per
cent. The only result from breathing such an excess of $\mathrm{CO}_{2}$ is a slight and unnoticeable increase in the ventilar $\mathrm{CO}_{2}$ is a slight and unnoticeable increase in the ventila-
tion of the lungs. The increased ventilation is exactly adjusted so as to keep the concentration of $\mathrm{CO}_{2}$ in the lungs at the normal 5 per cent of an atmosphere. Th very same thing happens when we take gentle exercise, and produce more $\mathrm{CO}_{2}$ in our bodies; the pulmonary ventilation is then slightly increased, and thus the $\mathrm{CO}_{2}$ concentration in the blood and lungs is kept at the same concentration in the blood and lungs is kept at the same
uniform level. At each breath we rebreathe into our lungs the air in the nose and large air-tubes (the dead lungs the air in the nose and large air-tubes (the dead
space air) and about one-third of the air which is inhaled into the lungs is "dead space" air. Thus, no ma breathes in pure outside air into his lungs, but air contaminated perhaps by one-third, or (on deep breathing) by one-tenth with expired air. When a child goes to sleep with its head partly buried under the bed-clothes, and in a cradle with the air confined by curtains, he rebreathes the expired air to a still greater extent. and with all animals that snuggle together for warmth's sake. with all animals that snuggle together for warmth's sake. Not only the new-born babe sleeping against its mother'
breast, but pigs in a stye, young rabbits, rats and mice clustered together in their nests, young chicks under the brooding hen, all alike breathe a far higher percentace than that allowed in our factories by the officials of the Home Office. To rebreathe one's own breath is a natural and inevitable performance, and to breathe some of the air exhaled by another is the common lot of men who, like animals, have to crowd together and husband their heat in fighting the inclemency of the temperate and Arctio in fighting the inclemency of the temperate and Arctic
zones. By a series of observations made on rats confined in eages with small ill-ventilated sleeping chambers, we have found that the temperature and humidity of the air -not the carbonic acid and oxygen concentration of the air-determine whether the animals stay inside the they like to stay inside, even when the carbonic acid rises to 4 or 5 per cent of an atmosphere. When the sleeping chamber is made too hot and moist they come outside. In breweries the men who tend the fermentation vats work for long hours in concentration of $\mathrm{CO}_{2}$ of 0.5 to 1.5 per cent. (Lehmann.) Such men are no less healthy and long-lived than those engaged in other processes of the brewing trade. In the Albion Brewery we analyzed on three different days the air of the room where the carthree different days the air of the room where the car-
bonic acid gas, generated in the vats, is compressed and bonic acid gas, generated in the vats, is compressed and
bottled as liquid carbonic acid. We found 0.4 per cent to over 1 per cent of carbonie acid in the atmosphere of that room. The men engaged therein worked twelvehour shifts, having their meals in the room. They had followed this employment for eighteen years, and without detriment to their health. It is only when we come to the higher concentrations of $\mathrm{CO}_{2}$, such as 3 per cent to 4 per cent of an atmosphere, that the respiration is in4 per cent of an atmosphere, that the respiration is in-
creased so that it is noticeable to the individual himself, and such percentages, of course, diminish the power to do work; for the excess of $\mathrm{CO}_{2}$ produced by the work adds its effect to the excess in the air, and the limit of panting is soon reached. Thus the power to work is checked. Divers who work in diving dresses, and men who work in compressed-air caissons, constantly work in concentrations of $\mathrm{CO}_{2}$ higher than 1 per cent of an atmosphere, and so long as the $\mathrm{CO}_{2}$ is kept below 2 per cent to 3 per cent of an atmosphere, they are capable of carrying out efficient work

It results, then, from what we have said, that concentrations of $\mathrm{CO}_{2}$, such as occur in the most crowded and worst-ventilated rooms, are of no account. Forced to admit this fact, the hygienist has fallen back on the hypothesis that organic chemical poisons are exhaled in the breath, and that the percentage of $\mathrm{CO}_{2}$ is a valuable guide as to the concentration of these. It is necessary, he says, to keep the $\mathrm{CO}_{2}$ below 0.1 per thousand, so that the organic poisons may not collect to a harmful extent.

Before we turn to the discussion concerning the supposed existence of these organic chemical poisons, we will deal with the question of oxygen. The oxygen in the worst-ventilated schoolroom, chapel, or theater, is never lessened by more than 1 per cent of an atmosphere. The ventilation through chink and cranny, chimney, door and window, and the porous brick wall, suffices to prevent a greater diminution of the oxygen concentraprevent a greater diminution of the oxygen concentra-
tion. Now, in all the noted health resorts of the Swiss tion. Now, in all the noted health resorts of the Swis
mountains, such as St. Moritz, the concentration of mountains, such as St. Moritz, the concentration of
oxygen is lessened considerably more than this. On the high plateau of the Andes there are great cities: Potosi, with 100,000 inhabitants, is at 4,165 meters (barometric pressure about 450 millimeters $\mathrm{Hg}$.); railways and mines have been built even at altitudes of 14,000 to 15,000 feet. Owing to the nature of the chemical combination of oxygen with hæmoglobin, man can adjust himself to very great variations in oxygen concentration. At Potosi girls dance half the night, and toreadors display their girls dance hall the night, and toreadors display their
skill in the bull-ring. We have watched our students, shut in an air-tight chamber, until they came to breathe air containing only about 16 per cent of oxygen and $3 \frac{1}{2}$ per cent of carbonic acid, and seen their puzzled look when they found they were unable to light a match and smoke a cigarette. There was then too low a percentage of oxygen to support combustion, but of this they were quite unaware. All the evidence goes to show that it is only when oxygen is lowered below a pressure of 14 per only when oxygen is lowered below a pressure of 14 per
cent to 15 per cent of an atmosphere, that signs of oxygen want arise. A diminution of 1 per cent of an atmosphere has not the slightest effect on our health or comfort. We must now discuss the evidence for the existense of organic chemical poison in the exhaled breath. The evil smell of crowded rooms is accepted by most as unequivocal evidence of the existence of such. This smell, however, is only sensed by, and excites disgust in, one who comes to it from the outside air. He who is inside and helps to make the "fugg" is both wholly unaware of, and unaffected by, it. Fluegge points out, with justice, that while we naturally avoid any smell that excites disgust and puts us off our appetite, yet the offensive quality of the smell does not prove its poisonous nature. For the smell of the trade or food of one man may be horrible and loathsome to another not used to such. The sight of a slaughterer and the smell of dead meat may be loathly to the sensitive poet, but the slaughterer is none the less healthy. The clang and jar of an engineer's workshop may be unendurable to a highly-strung artist or author, but the artificers miss the stoppage of the noisy clatter. The stench of glue-works, fried-fish shops, soap and bone manure works, middens, sewers, becom as nothing to those engaged in such, and the lives of th workers are in no wise shortened by the slench they enthe impulse, and the stench clearly does not betoken in any of these cases the existence of a chemical organic poison. On descending into a sewer, after the first ten minutes, the nose ceases to smell the stench; the air therein is usually found to be far freer from bacteria than the air in a schoolroom or tenement (Haldane.)

If we turn to foodstuffs, we recognize that the smell of alcohol and of Stilton or Camembert cheese is horrible to a child or dog, while the smell of putrid fish-the meal of the Siberian native- excites no less disgust in an epicure, who welcomes the cheese. Among the hardiest and healthiest of men are the North Sea fishermen, who sleep in the cabins of trawlers reking with fish and oil, and for the sake of warmth shut themselves up until the lamp may go out from want of oxygen. The stench of such surroundings may effectually put the sensitive, untrained brain-worker off his appetite, but the robust health of the fisherman proves that this effect is nervous in origin, and not due to a chemical organic poison in the air. The supposed existence of organic chemical poison in the expired air is based upon experiments of Brown-Sequard and d'Arsonval. They injected into guinea-pigs and rabbits either the condensation water obtained from the breath, or water which they used several times over to
wash out the trachea of dogs. The water was injected subcutaneously and in large amounts, and produced in their hands signs of illness, collapse and death.

These experiments have been repeated by many others, and with negative results by those whose methods of work demand most respect-Dastre and Loye, Van Hofmann Wellenhof, Lehmann and Jessen, Haldane and Smith, Weir Mitchell and Borgey, etc. A few confirmatory results have been obtained by methods of experiment which are truly absurd in their conception. One to two cubic centimeters of condensation water (obtained by breathing through a cooled flask) have been injected into a mouse weighing 13 grammes or so. This is equivalent to injecting 5 liters of water into $\Omega$ man weighing 65 kilogrammes. Who would not be made ill by the injection of about nine pints of cold water beneath his skin? It has been shown that injections of pure water alone in doses of over one cubic centimeter may make a mouse ill. (Inaha.) Such experiments are ridiculous, and deserve not a moment's attention.

In the case of Brown-Sequard's and d'Arsonval's experiments they injected from 4 to 44 cubic centimeters into guinea-pigs and rabbits, either directly into the circulation or subcutaneously. Using the washings of a dog's trachea, or the condensation fluid obtained from the breath, they could not fail to inject traces of the proteins of the saliva. A second injection of such into the same animal might produce the well-known anaphylactic shock. By subcutaneous injection of a foreign protein an animal becomes sensitized, and may be poisoned by a subsequent injection of the same. The sensitivity may be produced by extraordinary small doses - e. g., one millionth of 1 c.c. of serum. Anaphylaxis is never produced by the injection of protein taken from the same species of animal, nor can it be produced by eating foreign protein. There is no reason to suppose that it can be produced by breathing into the lungs traces of a foreign protein. Quite recently Rosenau and Amos have published experiments which seem to show that guineapigs can be sensitized by the injection of the condensation water of human breath, so that anaphylaxis is prodused in these pigs by a subsequent injection of a trace of human serum. These observers breathed for six to ten hours through a glass tube fitted with a plug of glass wool. $O$ wing to the method employed it seems certain that saliva must have wetted the glass wool, and, carried on in "droplet" form. contaminated the condensation water. Breathing through a tube leads to an expulsion of saliva which does not occur in natural breathing. The guinea-pigs, as we might expect, therefore became sensitized to human protein by the injection of the condensation water containing traces of salivary protein. The authors, however, do not take this view, and think that their results afford evidence in favor of the exhalation of a volatile protein - an organic chemical poison. We cannot admit this view. The question before us isDo men breathe out a substance poisonous to man? If there were anything in the claims of the American authors, we should expect to find rats, which dwell in the same confined cage and breathe each others' breath, sensitive to the injection of a trace of each others' protein. We are informed, by those who study the phenomena of anaphylaxis, that no such sensitivity can be shown.

After studying the literature on this subject we are convinced that there is no positive evidence which demonstrates the poisonous nature of the condensation water obtained from the breath. We go further and say there is at present no trustworthy evidence of the exist- 
ence of any such poison in the exhaled air. BrownSequard sought to substantiate his views by carrying out a different series of experiments. He arranged rabbits in a series of chambers, and led the air from one received the vitiated air from the one before it. In the end cage rabbits died, but if the air received into this end eage rabbits died, but if the air received into this
cage were passed through sulphuric acid, the rabbits remained alive:

These experiments have been repeated with the greatest care by Haldane and Lorrain Smith; also by Beu, Rauer, Lübbert and Peters, Billings, Weir Mitchell and Borgey, Formanek, etc. It has been proved conclusively that no harm results so long as a sufficient air current is maintained to keep the carbonic acid below a poisonous amount. The animal in the last cage dies when the $\mathrm{CO}_{2}$ reaches 10 to 12 per cent. If the $\mathrm{CO}_{\varepsilon}$ is kept down the animal in the last cage puts on weight and thrives as well as the animal in the first cage. Of course, it is necessary in such experiments to clean the chambers daily, and supply the animals with suitable food and bedding. We have repeated the experiments, in one case leading the air from a chamber containing three rats through a cham ber containing a guinea-pig, and in another case leadin the air from a chamber holding three rats through another chamber also holding three rats. The chambers were chamber also holding three rats. The chambers were
daily cleaned and fresh dry hay and food were put within The guinea-pig lived in an atmosphere containing about $31 / 2$ per cent of carbonic acid, and put on nearly 100 grammes in weight in three weeks, in this respect doin quite as well as another half-grown guinea-pig kept under normal conditions. The rats in the other second chamber did no less well. Thus the evidence obtained from this kind of experiment as to the existence of a poison in expired air is wholly negative. Brown-Sequard's result must be ascribed to sufforation arising from failure in must be ascribed to suffocation arising from failure in
experimental method. We accidentally lost four of our animals from suffocation after the experiment had continued for a month, owing to the chinking of a tube and consequent interruption of the air current. Benedic has shown that a man can live many days in a closed chamber in comfort without damage to his health, having not the slightest cognizance of any defect in ventilation when the ventilation is so reduced that the carbonic acid accumulates in the chamber up to 1 per cent-that is to say, so long as the air in the chamber is kept cool and dry. We have inclosed eight students in a small chamber holding about three cubic meters of air and kept them therein until the $\mathrm{CO}_{i}$ reached 3 per cent to 4 per cent, and the oxygen had fallen to 17 or 16 per cent. The wetbulb temperature rose mean while to about $85 \mathrm{deg}$. Fahr., Who higher. The discomfor was very great, but this was relieved to an astonishing extent by putting on electric fans placed in the ron,
whirling the air in the chamber, and so cooling the bodies whirling the air in

of the students. and clothes of the people is almost warmed up to body temperature and saturated with moisture, so that coolin of the body by radiation, eonvection by evaporation, becomes almost impossible. This leads to sweating, wetness and tushing of the skin, and a rise of skin temperature. The blood is sent to the skin and stagnates there instead of passing in ample volume through the brain and viscera. Hence arise the feelings of discomfort and fatigue. The fans in our chamber whirled away the blanket of stationary wet air round their bodies, and brought to the students the somewhat cooler and drier air in the rest of the chamber, and so relieved the heat stagnation from which they suffered. The relief became far greater when we allowed cold water to circulate through a radiator placed in the chamber, and so cooled the air of the chamber about $10 \mathrm{deg}$. Fahr.

Messrs. R. A. Rowlands and H. B. Walker have carried out, with us, numerous experiments in this chamber. They have performed measured amounts of work (raising a weight) under varving conditions of temperature moisture, and with

As a measure of the exhausting effect of the work, we have counted the frequency of the heart-beat in the first, second and third minute after the completion of the work. When the work is done without over-fatigue the frequency of the pulse, which is accelerated by work, quickly returns to normal. Our results show that increased percentages of $\mathrm{CO}_{2}$, and diminished oxygen percentages of 2 per cent to 3 per cent and even 4 per cent to 5 per cent, have little effect in modifying the frequency of the pulse, while the temperature and humidity of the air have a profound effect. The feelings of discomfort depend on the excessive heat and humidity, and are depend on the excessive heat and humidity, and are
relieved by cooling and whirling the air in the chamber. relieved by cooling and whirling the air in the chamber.
If we suddenly raised the percentage of $\mathrm{CO}_{2}$ in the chamber up to 2 per cent we found the subjects inside were quite unaware of this. If we sat outside and breathed through a tube the air in the chamber we felt none of the discomfort which was being experienced by those shut up inside. Similarly, if one of those in the chamber breathed through a tube the pure air outside he was not relieved. Similar experiments were carried out by Paul, and with like results. The cause of the discom- fort is thus proved to be due to the excessive heat and humidity, and absence of movement of the air. Studying the ventilation of sleeping-cars, T. R. Crowder finds that in these cars, called "close" or "stuffy," the temperature invariably is high. There has sometimes been an unpleasant odor. A high temperature renders this more noticeable. The most marked offensiveness noticed was noticeable. The most marked offensiveness noticed was
in a day coach, where "the air was of such a degree of chemical purity as to indicate ideal ventilation by any standard that has ever been proposed. The car was hot and had many filthy people in it." Perfect comfort has been found associated with the highest chemical impurity in other cars.

After healthy and clean students have been shut in our chamber

Ventilation cannot get rid of the source of a smell, Ventilation cannot get rid of the source of a smell,
while it may easily distribute the evil smell through a ouse.

As Pettenkofer says, if there is a dungheap in a room, it must be removed. It is no good trying to blow away bodies must be made clean, and latrines and kitchens placed on the top of houses, or outside them, and on the windward side. There is yet another aspect of ventilation which we have not yet discussed, viz., bacterial infection. Catarrhal infections are spread by the expulsion of droplets of saliva when speaking, coughing or sneezing. During quiet respiration the exhaled breath is practically sterile, for the wet mucous surfaces of the respiratory tract catch all the inhaled bacteria, and no "droplets" are exhaled. Can we lessen the "droplet" infection by ventilation? Fluegge concludes, from the results of his admirably contrived experiments, that we cannot. He says a current sufficient to drive out such droplets cannot be borne by the inhabitants of the room. A moderate ventilation current tends to keep the droplets suspended in the air. In a still room they soon fall to the ground, and, clinging to floor and furniture, may b wiped up next morning and removed by the housemaid.

We cannot hope to prevent infection in crowded raildemics of munity show this only too well.

It is impracticable to isolate all those suffering from colds, but we can teach them at least to cough and sneeze into a handkerchief, and perhaps even talk with a handkerchief in front of their mouths. Above all, we must seek to keep up our immunity and resist infection. Im-
munity depends on the quality and flow of the blood, the supply of immunizing substances in the tissue lymph, the activity of the ciliated epithelium and phagocytes which form a seeond line of defense against bacteria. The state of all these defensive mechanisms of the respiratory membranes are modified by the temperature and relative humidity of the air. Exposure to over-heated dry air dries up not only the skin but the membranes of the nose and throat, and so lessens immunity.

Exposure to over-heated moist air brings the blood into the skin, lessens the circulation through the viscera,
and deprives us of the stimulating effect of cold on the cutaneous nerves, decreases the evaporation from the respiratory tract, diminishes the muscular activity, and respiratory tract, diminishes the muscular activity, and
so the amount of oxygen breathed in and food eaten, and thus altogether lowers the plane of our existence. Hence arise diminished health, strength, and increased susceptibility to catarrh. Those who habitually expose themselves to cold rarely take cold.

Confinement in over-heated, windless air, which too of ten pervades places of business and amusement, is one of the chief causes of the depressed physical and mental vigor of town dwellers. The evidence of daily life proves that those who take hard exercise in the outside air for some hours a day escape these ill effects. The health of sailors and country laborers shows us that sleeping in hot, confined and ill-ventilated quarters is of no consequence if the working day is spent in the open air. It is persistent exposure to the uniformity of warm, windless air which is the cause of the mischief. The conditions of great cities the heated atmosphere of the club, cinema show, or music-hall in the evening. The height of the houses prevents the town dweller from being blown upon by every wind of heaven, and, missing the wonderful exhilaration of the cool, moving, open air, he repels the dull uniformity of his existence by the moving pictures of the showman and by tobacco.

We have now dealt with the general principles which ought to control the practice of the heating and ventilating engineer. The old English methods of open fire and open window have very much to recommend them. By the open fire air is kept moving and cool air is brought in; the heating is by radiation, and uniformit of the conditions of temperature in the room is prevented On the other hand, the impulsion of hot air into a room is the most objectionable of all the systems employed. A cool air and radiant heat are the ideal; the hot-air system gives us neither. In cold weather the heated air becomes Americe have been eriously undermined by the impul sion of hot "desert air" into the schools.
We are now in a position to examine the uses of ozone in ventilation. Ozone is represented by $\mathrm{O}_{3}$, and differs from the oxygen molecule, $\mathrm{O}_{2}$, by the addition of a third oxidizing properties. It corrodes cork, rubber, and other organic substances, and oxidizes iron, copper, and even silver when moist, and dry mercury and iodine. Galvanized iron tubes or glass can be used for the conductance of ozonized air. Traces of ozone are found in the atmosphere after thunderstorms, produced by the effect of the electric discharge on atmospheric oxygen. It is said that traces of ozone exist in sea and mountain air. Ozone is generated by the silent discharge of high-tension currents from one plate of metal to another across a sheet of insulating material. In the Ozonair apparatus the metal plates are sheets of fine gauze separated by micanite. The discharge takes place from the multitude of points on the gauze, and this equalizes the tension at which the discharge takes place, prevents sparking and the formation of oxides of nitrogen. These oxides contaminate the ozone which is formed when ordinary smooth plates are employed, for the discharge then takes place at a few It is said to be the sparking discharge in air which causes the oxides to form. Each complete element of the Ozonair apparatus consists of a thin sheet of micanite, covered on each side by a square of gauze. The air can be made to pass by a series of baffle plates over a series of these elements. There are over 230,000 round projections to the square foot of the gauze, from which discharge takes
place. The gauze is made of an aluminium alloy of forty place. The gauze is
meshes to the inch.

The Ozonaiz Company have placed their apparatus at our use, and we must thank Mr. Edward L. Joseph for his courtesy and assistance in the carrying out of our inquiry. The concentration of ozone can easily be determined by aspirating a 10-liter sample of the air through an acidulated 1 per cent solution of potassium iodide. A little fresh starch solution is added to this. The ozone turns it blue. Titration is carried out with a standard solution of hyposulphite of soda.

On exposing mammals to different concentrations of ozone in our chamber, we have found they may be killed by prolonged breathing of concentrations of about twenty parts per million. The cause of death is an acute irritative inflammation of the respiratory tract. After death congestion of the lungs is found. The ozone in such concentrations causes the eyes to water and makes one cough. It is so irritative and unpleasant that no one would think of continuing to breathe it. Thus a man cannot be poisoned unawares by a dangerous concentration of ozone. He will certainly remove himself from its presence. No harm results from breathing such concentrations for a short period. A slight irritation of the respiratory tract and some sneezing and coughing, and perhaps headache, are the only penalties. The danger signals are clearly set by ozone, and anyone must naturally obey them. When ozone is employed in ventilation it is arranged in such a concentrat

Oxygen in high concentrations (at two or three atmospheres of pressure) is also a poison, and produces not only acute congestion of the lungs, but convulsions. Unlike ozone, oxygen produces no preliminary irritative effect. The breathing of ozone in suitable weak concentrations is no less safe than the breathing of proper concentrations of oxygen. Certain insects are comparatively immune to the effects of high concentration of ozone. For example, we have found that fleas stand exposure to is very unfortunato. Had these parasitic insects proved highly susceptible we should have found in ozone a clean and ready method of attack.

Ozone can be used in high concentrations for sterilizing water; and herein is to be found one of its most valuable uses. The water is not only sterilized but oxygenated, and ozone can be used, therefore, with great advantage to keep the water of aquaria in good condition. Ozone has been successfully applied as the means of purifying the water-supply of several towns, both abroad and in this country. Where the water-supply is contaminated and the source of electric power is cheap, no better or simpler method can be employed. Ozone is a most powerful deodorizer. It takes away all disagreeable smells Whether it destroys them or prevents the nose smellin them, is of little importance. The psychical effect is the same-the disgust due to the evil smell disappear Ozone itself has a peculiar smell. It reminds one of the fumes of nitric acid, and whether the smell is that of ozone or minute traces of oxides of nitrogen, it is difficult to say. The nose may detect what the analytical methods of the chemist fail to show. By the smell we can detect concentrations of far less than one part in a million, and the smell is the safest and easiest guide to a suitable concentration. Ozone should be present in the air for continuous breathing in concentrations not greater than that scarcely perceptible to the smell. Concentraand quickly one part in the million are too irritative, perature of rats, and aro unploasant to perature of rats, and are unpleasant to man. Very weak
concentrations, barely perceptible to the smell, have no 
ill effects, but destroy the effect of unpleasant smells and give a certain tang or quality to stuffy air which relieves its monotony and uniformity.

It is in this respect that ozone has its use. There exist in modern conditions of life so many trade shops, tube railways, cold meat stores, etc., where the employees are exposed to a persistent, uniform and depressing smell. The air in many buildings is made to smell by the heating The air in many buildings is made to smell by the heating
appliance used. The addition of ozone takes away the appliance used. The addition of ozone takes away the
smell and relieves the monotony of such air, and, as the Ozonair apparatus can, by the turning of a switch, be put in or out of use, the uniformity of the atmospheric conditions can thus be frequently changed. The ozone, no doubt, exerts its effect both on the cutaneolis and respiratory nerves.

We have not been able to obtain any evidence that ozone in weak concentrations influences the respirator metabolism of the resting man. We have studied the effect of ozone both on animals and on ourselves, estimating the amount of oxygen used up and carbonic acid produced during successive periods of time when air or ozonized air was breathed.

The rate of oxidation of the human body is set by the nervous system, which controls the activity of the body. Breathing pure oxygen in place of air has no effect on the metabolism of the man at rest. It will increase the metabolism of a man doing hard work, but only in the case of his working so hard that he suffers from a shortage of oxygen when breathing air. The body, unlike a fire, cannot be fanned up to burn faster. The living substance works at its own rate independent within wide limits of the changing conditions of the outside world. We should not expect, therefore, that ozone would stimulat the metabolism of the resting man. By altering the unpleasant uniformity of a close atmosphere it may help an employee to work more briskly. In high concentrations, ozone, just as high concentrations of oxygen, depresses ozone, just as high concentrations of oxygen, depresses the metabolism because it is toxic to the cells of the
respiratory tract. The ozono which is breathed into the ungs is caught by the wet mucous membranes and none of it is exhaled. It is, no doubt, used up there in an oxidative process of the tissues. It is excess of such oxidative process which damages. the cells lining the respiratory tract, when either too great a concentration of ozone (or oxygen) is breathed. There is no evidence that ozone reaches the blood, or that it has any other influence on the body. The effect which ozone in weak concentration has on the olfactory nerves, and those of the skin and respiratory tract, is the justification for its use in ventilation.

\section{The Steam Locomotiv}

"The steam locomotive continues to be the most fascinating of all the varied studies presented by engineering," says The London Times. "Now and again its pre-eminence may for a moment be threatened either by the brilliant performance of a rival means of propulsion or by the predictions of a theorist, but notwithstanding all that is said and done and written, it withstanding all that is said and done and written, it
continues to reign supreme in its own sphere of usefulness. In seeking for a reason for its persistence, it is realized that the locomotive has a remarkable power of adapting itself to the requirements of the designer, and that it has potentialities that constitute a wealth of reserve force. Within recent years it has been called upon to increase its power, alike for passenger and goods service, and this demand has been met partly by the introduction of higher boiler pressures, and partly by increase of the dimensions of cylinders. Loads, speeds, and lengths of run have become more exacting and the costs departments have simultaneously directed their efforts toward economies. To meet these requirements, the mechanical engineers of railway companies have been led to investigate the merits of such devices as depend upon the use of oil fuel, compounding, and the adoption of superheating of steam, and it is to be observed that the progressive movement is now in evidence among even the most conservative users and designers. In the matter of superheating, Great Britain is generally regarded as being behind the Continent, and in any case it must be acknowledged that German and Belgian engineers have done praiseworthy work in developing the superheater into a satisfactory appliance for loeomotives. At the same time it is fair appliance for locomotives amount of steady experimental work has been in progress for some time, and that the grest accession of superfor some time, and that the great accession of superheaters to British locomotives is the result of careful
scrutiny of a very complex question of ways and means. When the proposal to use superheaters for this purpose was first put into practical shape there were great difficulties to be overcome, and it was not desirable to adopt such devices in their original forms. Their use was, in fact, attended by a certain degree of risk, and was, in fact, attended by a certain degree of risk, and the designer is able to record a complete victory, with the designer is able to record a complete victory, with
consequent increase in power, lower cylinder pressures, and greater flexibility to meet the heavy' demands that fall upon the most willing of all propelling agents, with the result that the steam locomotive has been given yet another lease of life."
Trade Notes and Formula

To Clean Panama Hats. - Concerning the cleaning of Panama hats, we cull the following information from Phar. Ztg.. No. 63, 1910. Sodium perborate has proved Phar. Ztg.. No. 63, 1910. Sodium perborate has proved
an excellent agent for the bleaching of Panama hats, a solution in the following proportions being used: Sodium perborate 30 parts, lukewarm water 4,500 parts. Proceed as follows: Wash the hats with soap and warm water with the aid of a brush, to remove the dirt adhering mechanically. After a thorough washing off with water, they are to be immersed in the above-described bleaching bath and left in it for 24 hours, care being taken that the hat fabric is continuously covered by the fluid; any part of the hat that projects beyond the fluid will be stained brown, and the color cannot be removed. It is advisable, however, to stir the bath now and again. Finally, the bleaching bath must be heated to 50 to $55 \mathrm{deg}$. Cent. (122 to $131 \mathrm{deg}$. Fahr.). Then transfer the hats to a solution of 30 parts of oxalic acid in 4,500 parts of thorough rinsing in clear water, it is best to dry the hats in the sun. An enameled vessel is to be preferred for the in the sun. An enameled vessel is to be preferred for the
bleaching bath, but a wooden tub or an earthenware bleaching bath, but a
vessel may also be used.

Silver Gray for Straw Plait.-Boil white or bleached straw hats for two hours in a solution of 2,000 parts of pure alum, free from iron, and 100 parts of tartaric acid, pure alum, free from iron, and 100 parts of tartaric acid, and indigo carmine, with a little sulphuric acid.

Stucco Marble for Walls, Columns, etc.-Apply to the rough fresh lime finish, a mortar composed of white or colored wall plaster, smooth it off, and when perfectly dry, coat it with a mixture of 7 parts wax, 2 parts stearine, dry, coat it with a mixture of 7 parts wax, 2
and 20 parts oil of turpentine, applied hot.

Stucco for Ornaments. 4 parts plaster, 3 parts white lime, 3 parts fine white sand mixed with glue water. If the mass is to be colored, the colors (earth colors and metallic colors) should be mixed dry with the plaster in a tumbling barrel.

Stucco Lustro (in the Vienna houses of parliament).1 part lime, 2 parts of marble dust, applied with a rubbing board, rubbed down with wooden sticks and smoothed with a polishing trowel. For polishing take 2,000 parts of water, 90 to 110 parts of wax, 40 to 46 parts of soap, and 20 to 25 parts of potash; dip in the mixture a woolen rag and rub with it.

Bronze Imitations with Plaster or Wooden Models. Plaster or wooden models, when they have fulfilled their purpose, are, as a rule, laid aside and entirely ignored. What can be done with them, anyway? A shaped wooden or plaster model is no presentable article, especially in the opinion of the lay public. It is painted with shellac, soiled with molding sand, in a word it has no eslor. How much more beautiful and sightly is such a figure when properly and skilfully treated with color. The figure undoubtedly cost much, in work and outlay, and on general principles we would preserve it. And for this reason it may be readily understood, says the

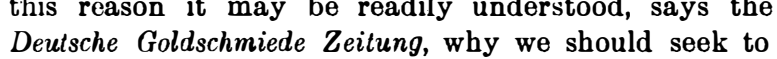
preserve many pieces of this kind in a new dress, make it presentable, so that it may be evidence of the ability and industry of the maker, of the productions of the concern, and last, but not least, that we ourselves may find pleasure in it.

An elegant and most suitable method of coloring such figures, is to convert them into imitations of bronze. The plaster model we have before us is worth the little trouble and, therefore, we may color it, in dark bronze or iron-bronze, according to the following method. The model having been freed from dust is coated with ordinary varnish, applied, two or three times with a brush. As soon as the varnish has dried in, the model is coated with a copper or gold bronze, soluble in oil. After this color is dry, mix powdered graphite with some oil and varnish and apply the mixture, to cover evenly. Careful work will give the piece a dull shining appearance. Wo work will give the piece a dull shining appearance. We places, or the noticeably projecting parts of the piece from the graphite coating, until the bronze coating is again visible. Care must be taken not to rub too much or the effect of the object as a whole will suffer and it will lack repose.

Another process is to mix brown shellac, dissolved in alcohol, with umber or Cassel brown and coat the figure with this mixture, applied as thinly as possible, until, after drying, the object assumes a uniform dull appearance. The plaster model is then placed near the stove so that it is warmed through and through. . This is necessary for the last process. Fluid, heated wax is thinne with oil of turpentine, Cassel brown or umber added and the warm model painted with the mixture. After cooling, the strongly prominent or raised parts are polsshed, by rubbing with a soft brush, and some zinc-green is applied or dusted into the deep places.

In both the two last described processes, the dustin or painting of the deep spots, with a little zinc-green, or verdigris, heightens the effeet. Wood models may be treated in the same manner as plaster.

Science Notes

Athletes and Long Life. - In answer to the query Do athletes die young?" Dr. William G. Anderson, director of the Yale University gymnasium, has given the results of a study of the college records for fifty years A comparison of the mortality of specialized athletes with the general graduate who has not distinguished himself in athletics shows in favor of the athlete. Of 10,922 students in academic and Sheffield classes from 1855 to 1905 inclusive, 1,406 have died, and 9,516 are still living. This shows the percentage of deaths to be 12.9 per cent. Of the 207 athletes from 1855 to 1905 only 58 are dead, a percentage of 7.2 , or a little over hal that of the general graduates. Dr. Anderson concludes that the Yale athletes do not die young, nor is heart disease a leading cause of death in them. Lung trouble is the cause of the greatest number of deaths, but the percentage of men dying from these causes is not greater than the expected death rate among non-athletes from similar causes. However, although the athlete is not short-lived, the statement is not warranted that he owes his longevity to athletics.-Medical Record.

Glass Highly Permeable to X-Rays.-As is well known $\mathrm{X}$-rays have their origin in Crookes tubes at the point where the cathode rays impinge upon an obstacle, such as the anti-cathode. They differ from ordinary light, probably in that they are constituted of short pulses rather than continued waves. Now it so happens that the tubes which are used to produce X-rays, themselves absorb a considerable portion of these; in fact, from 52 to 70 per cent, supposing the glass to be 7 millimeters thick. According to the ideas of J. J. Thomson and his school, the degree of absorption depends mainly on the atomic weights of the elements entering into the composition of the glass. The idea therefore presents itself to use glass of a suitable composition, so as to reduce the amount of absorption. This has been done by the use of a glass containing boron, lithium and beryllium, in place of silicon, sodium and calcium. From the following table it will be seen how the atomic weights of these substances are related to one another:

$\begin{array}{llr}\text { Silicon, 28 } & \text { Boron, } & 11 \\ \text { Sodium, 23 } & \text { Lithium, } & \mathbf{7} \\ \text { Calcium, 40 } & \text { Beryllium, } & 9\end{array}$

Calcium, $40 \quad$ Beryllium, 9

The new glass which is obtained is found to be five times more permeable than ordinary glass to $\mathrm{X}$-rays of medium hardness. Unfortunately, this glass is rather rapidly corroded by the air. This effect can be in some measure avoided by coating it with a thin film of gumlac varnish.-Cosmos.

We wish to call attention to the fact that we are in a position to render competent services in every branch of patent or trade-mark work Our staff is composed of mechanical, electrical and chemical experts, thoroughly trained to prepare and prosecute all patent applications, irrespective of the complex nature of the subject matter
involved, or of the specialized, technical, or scientific
knowledge required therefor.

knowledge required therefor.

We are prepared to render opinions as to validity or arising in trade-mark and unfair competition to conflic

We also have associates throughout the world, who assist in the prosecution of patent and trade-mark applications filed in all countries foreign to the United States. MunN \& $\mathrm{Co}$ Palent Allorneys,

Branch Office (j3 Broadway,

625 F Street, N. W.,

Washington, D. C.

TABLE OF CONTENTS

The Elba Iron Ore Loading Plant.-5 illustrations.... 337, 344

The Present Status of the Diesel Engine in Europe..-III.-

By Dr Rudolph Diesel.

The Strength of Large Ships.

-By stanley Yale Beach.

Ee Effect, of Frost on Plants.-By Our Berlin Correspond-

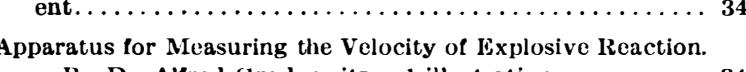

- By Dr. Alfred Gradenwitz. -1 illustration..........
e Origin of Radium.-By Frederic soddy, F.R.S. -4 illus-

trations. .

The Pod-septum of Catalpa.-2 illustrations.

The New Los Angeles Waterworks.-By W. H. Ballou.-2

illustration

team Turbo-Generator station. -5 illustrations........ 348

asoline Engine with Auto-Ignition.-By A. N. Low.-1

The Influence of Ozone on Ventilation.-By Leonard Hill,
B.M., F.R.S., and Martin Flack. M.A., M1.B., B.(Ch... 350

The Steam Locomotive. . . . . . . . . . . . . . . . . . . . . 35

Trade Notes.

352 